\title{
PATTERN AND PREVELANCE OF NEONATICIDE IN CAIRO GOVERNORATE DURING TWO YEARS (2008-2009): A RETROSPECTIVE - DESCRIPTIVE STUDY.
}

\author{
Dina A. Shokry*, Ayman H. Kamar** and Abdelrahman Torky** \\ *Department of Forensic Medicine and Clinical Toxicology, Faculty of Medicine, Cairo \\ University; **Department of Forensic Medicine and Clinical Toxicology, Faculty of \\ Medicine, Helwan University
}

\begin{abstract}
Background: The term neonaticide describes the act of killing a newborn child by a parent (mostly the mother) within twenty-four hour after birth. Neonaticide is the commonest murder ever practiced throughout history. Different motivational factors leading mothers to commit neonaticidal acts including social, socio-economic and psychological factors. Aim: The aim of this work was to clarify the extent of this crime in the Egyptian capital; Cairo Governorate, in order to obtain an imagination about the real extent of the problem through a comparison with similar studies in other cultures. Methodology: seventy five neonatal deaths referred to Cairo Morgue during two years (2008-2009) included in this study, all were died within twenty four hours after birth. Reports' data were retrospectively studied and analyzed. Results: The study included seventy five neonates; thirty one males $(41.3 \%)$ and forty three females $(57.3 \%)$ and one case whose sex couldn't be determined. Regarding the neonaticides; three cases were males $(20 \%)$ while twelve cases were females $(80 \%)$. The results revealed that $(20 \%)$ of the cases were diagnosed as homicidal i.e. neonaticides, and $(66.7 \%)$ were diagnosed as accidental and pathological, while in $(13.3 \%)$ the manner of death could not be determined. Forty-five cases $(60 \%)$ had been born at full term and thirty cases $(40 \%)$ prematurely. Regarding the cause of death, twenty four cases (32\%) died due to prematurity and low birth weight; nineteen cases $(25.33 \%)$ were died due to head injury and cerebral hemorrhage; of which six cases were neonaticidal (32\%), while death due to respiratory problems and cardiovascular causes accounted for thirteen cases (17.30\%). Violent asphyxia was diagnosed in five cases $(6.70 \%)$, all were homicidal (neonaticide) and omission was accounted for three cases (4\%). Hemorrhagic shock was the cause of death in one case $(1.33 \%)$ and it was homicidal. Fetal malformation accounted for one case (1.33\%). Conclusion: We concluded that neonaticide is a problem in Cairo governorate. The problem must be thoroughly investigated and carefully studied from different perspectives in order to achieve a reasonable solution.
\end{abstract}

Key words: Neonaticide, Neonatal death, Birth trauma, Gender selection

\section{INTRODUCTION}

Throughout history, a strong relationship had been found between increase neonatal deaths and different social problems (Bätje et al., 2011).

Neonaticide is a painful problem that may confront any society. Increase prostitution in a community with obstacles facing the marital process reflects this type of violence which is directed against those who are not considered full human equals (Piers, 1976).

The subject of neonatal deaths is 
met with the society that practices gender selection. On the other hand, that society may also prosecute a mother for killing her infant (Spinelli, 2005).

The maternal killing of children constitutes a complex phenomenon which has been reported across numerous cultures throughout history, with various causes and characteristics. As prevention implies the recognition of causes involved in particular situations, a better understanding of the dynamics leading to killing a neonate could facilitate the identification of the risks and enable effective interventional strategies (Bourget et al., 2007).

The term "neonaticide" describes the act of killing a newborn child by a parent (mostly the mother) within twenty four hours after birth

(Schöne et al., 2015).

Neonaticidal mothers often deny or conceal their pregnancies and usually are not mentally ill, thus they generally avoid contact with medical professionals. Unmarried women usually hide their pregnancies, deliver and abandon their babies, and later are rushed to the hospital with postdelivery complications (West, 2007).

The parental killing of children constitutes a complex phenomenon which has been reported across numerous cultures and throughout history (Spinelli, 2005).

The religion of the Ancient Egyptians forbade infant killing and during the Greco-Roman period they rescued abandoned babies from manure heaps, a common method of infanticide by Greeks or Romans, and were allowed to either adopt them as foundlings or raise them as slaves, often giving them names such as "copro -" to memorialize their rescue (Teeter, 1999).
Infant killing is explicitly prohibited in Islam by the Qur'an: "And do not kill your children for fear of poverty; we give them sustenance and yourselves too; surely to kill them is a great wrong" The Holly Qur'an, Israa17 (Encyclopedia of the Qur'an, 2016).

The aim of this work was to clarify the extent of this crime in the Egyptian capital; Cairo Governorate through analysis of the records of neonaticides during two years 2008 2009 and through a comparison with similar studies in different communities approaching an imagination about the extent of the problem which is the first step towards the solution. Incidence, method of violent incident infliction and criteria for forensic investigation and diagnosis were taken into consideration during the study.

\section{SUBJECTS \& METHODS:}

Studying and analyzing seventy five cases of neonatal deaths reported and delivered to Cairo Morgue; Egyptian Forensic Medicine Authority during two years 2008-2009 throughout a retrospective and descriptive study of the data recorded was done.

According to the definition of neonaticide, deaths of more than twenty four hour duration, extra-uterine life time, were excluded during this study. Also antenatal or intra-natal causes of death were excluded.

All cases were subjected to external examination, full autopsy, and histopathological and toxicological examinations (when needed).

Detailed medicolegal report was issued for each case including the circumstantial evidences, as were informed by the investigating authorities, all examination findings and an opinion about the cause and 
manner of death as well as the gestational age and the estimated time since death.

The following points were investigated during the study:

- Assessment of extra-uterine lifetime

- Assessment of fetal maturity

- Gender assignment

- Determining cause of death

- Identification of the death manner

- Determination of the type of incident (in homicidal cases)

Assessment of extra-uterine life time depended mainly on detecting absence of any vital reaction around the base of the umbilical cord, persistence of vernix caseosa, caput saccidaneum changes and presence of meconium (Schulte et al., 2013).
LIMITATIONS OF THE STUDY

The investigating authorities usually don't inform the medicolegal examiner about the progression of the investigation, so there is no enough data about the perpetrators.

\section{RESULTS}

Seventy- five neonatal cases were recorded and examined in Cairo

Morgue; Egyptian Forensic Medicine Authority during two years 2008 -2009. According to the diagnosed manner of death, fifteen cases $(20 \%)$ were found to be homicidal i.e. Neonaticides; fifty cases $(66.7 \%)$ were found to be accidental and pathological, while in ten cases $(13.3 \%)$ the manner of death was undetermined (figure: 1 ).

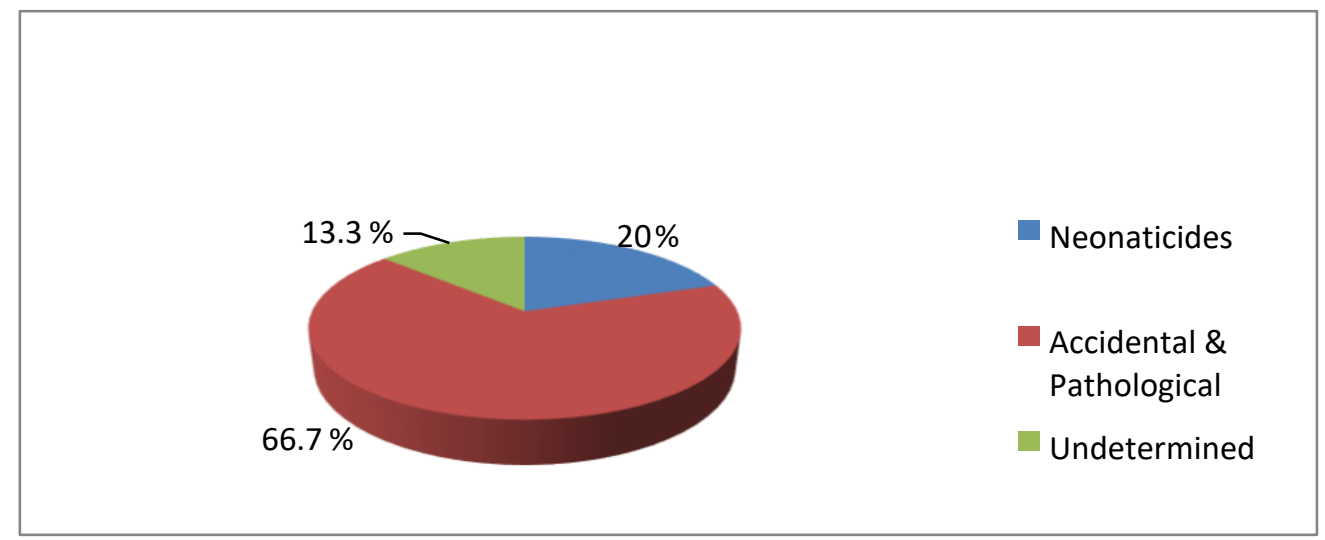

Figure (1): Classification of cases according to manner of death

Thirty-one cases were found to be males $(41.3 \%)$ and forty three cases were females $(57.3 \%)$. In one case, the sex couldn't be determined due to advanced putrefaction. Regarding the neonaticides; three cases were males $(20 \%)$ while twelve cases were females (80\%); (Figure: 2). 


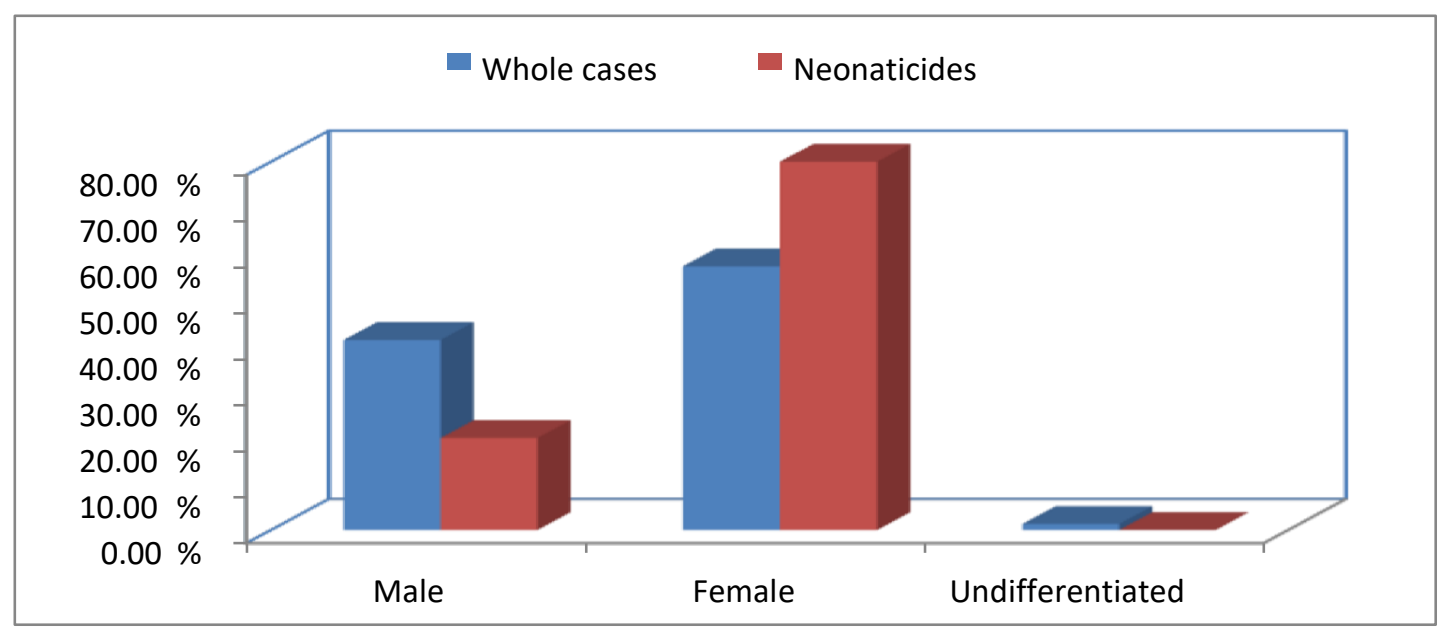

Figure (2): Gender classification according to manner of death

Forty five cases were found to be full term $(60 \%)$, while thirty cases were preterm (40\%). Out of all neonaticides, eleven cases were full term $(73.33 \%)$ while four cases were preterm (26.67\%); (Figure: 3 ).

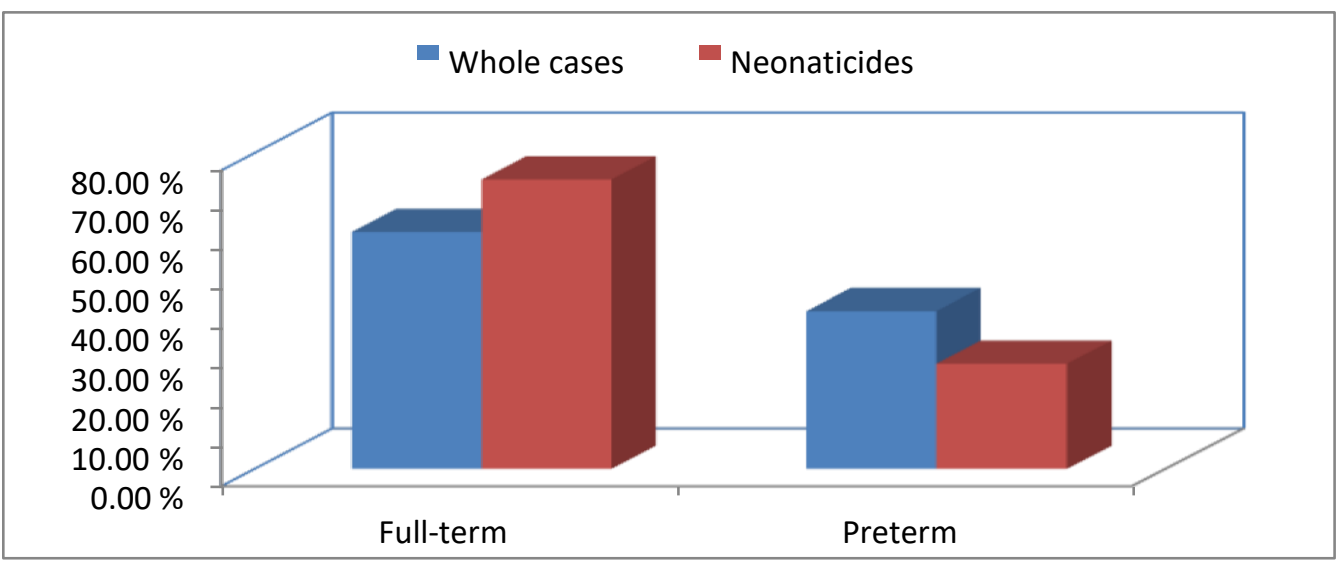

Figure (3): Classification of cases according to gestational maturity

\section{(Figure: 4);}

- As regard the cause of death

Violent asphyxia was diagnosed in five cases $(6.70 \%)$, all were homicidal. While omission accounted for three cases (4\%); all were classified as homicidal.

Nineteen cases $(25.33 \%)$ were diagnosed to be due to head injury and cerebral hemorrhage; of which six cases were homicidal (32\%) and thirteen cases (68\%) were nonhomicidal.

Death due to respiratory problems and cardiovascular causes accounted for thirteen cases $(17.30 \%)$; of which none was homicidal.

Twenty four cases (32\%) were diagnosed to be due to prematurity and low birth weight; of which none (0\%) is referred to homicides.

Hemorrhagic shock was the cause of death in one case $(1.33 \%)$ and was classified to be homicidal. While fetal malformation accounted for one case $(1.33 \%)$ and was non-homicidal.

In nine cases $(12 \%)$, the cause of death couldn't be determined due to advanced putrefaction. 


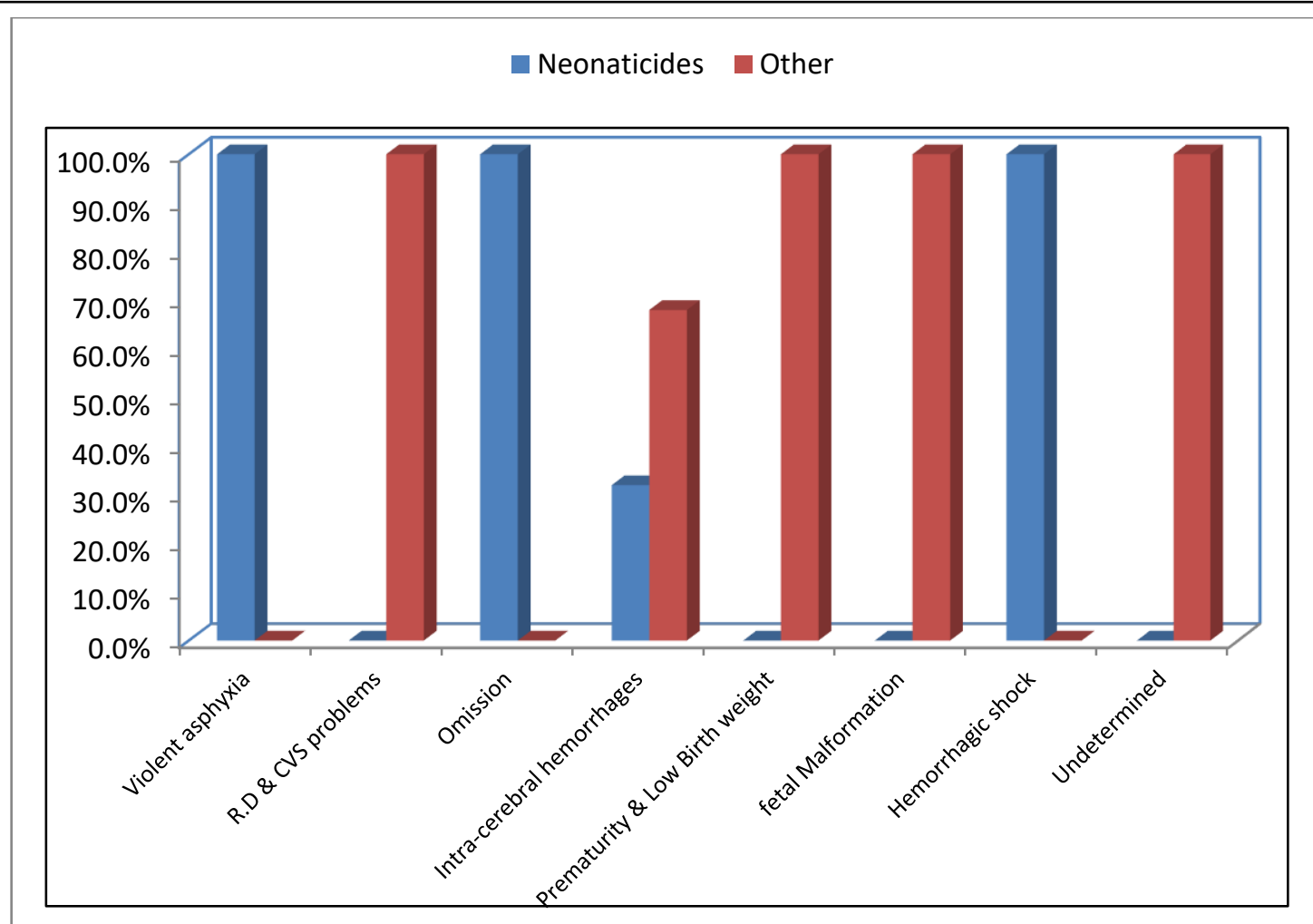

Figure (4): Classification of cases according to cause of death

Regarding the methods of violent incident infliction for the neonaticides (table: 1); blunt trauma (mostly to the head) accounted for six cases $(40 \%)$. Usually, many other injuries appear scattered on the newborn body which excludes the possibility of death due to birth trauma.

While five cases were referred to asphyxia (33.3\%); of which three cases were due to strangulation and two cases were due to smothering, while gagging, traumatic asphyxia, suffocation drowning was not encountered in this study.

Also table: (1) shows that three cases were referred to omission $(20 \%)$ by neglecting feeding, clothing, cutting the umbilical cord either separately or combined. Cut throat was seen in one case $(6.70 \%)$.

Table (1): Methods of violent incident infliction for the neonaticides

\begin{tabular}{|l|c|c|}
\hline \multicolumn{1}{|c|}{ Type of Incident } & No. & $\%$ \\
\hline Blunt trauma & 6 & $40 \%$ \\
\hline Cut \& stab wounds & 1 & $6.7 \%$ \\
\hline Omission & 3 & $20 \%$ \\
\hline Asphyxia: & & \\
\hline - Strangulation & 3 & $20.0 \%$ \\
\hline$-\quad$ Smothering & 2 & $13.3 \%$ \\
\hline - Gagging & 0 & $0.0 \%$ \\
\hline - Traumatic asphyxia & 0 & $0.0 \%$ \\
\hline - Suffocation & 0 & $0.0 \%$ \\
\hline
\end{tabular}




\section{DISCUSSION}

Neonaticide being an extremely traumatic criminal act has psychopathologic repercussions and socio-familial consequences. It is marked by its plurality of forms, the variety of its aspects and the frequency of its hidden cases. Circumstances and modes of completion of the infanticide act are variable according to the nature of the author and the socio-cultural context (Rammouz et al., 2008).

Regarding the methods of violent incident infliction in the present study, results showed that blunt trauma to the head with subsequent cerebral hemorrhages was the commonest method of neonaticide (40\%) followed by violent asphyxia (33.3\%), then omission (20\%), while cut throat accounted for $6.7 \%$ ) of neonaticides.

In a study in Japan by Taguchi, (2007), a judicial sample of 96 adult women, convicted in their first trial for the murder or attempted murder of their children were divided into four groups of mothers according to the age of the victim (25 women killed neonates, 22 women infants, 27 women preschool children, and 22 women schoolchildren and/or teenagers). Neonaticide cases were distinguished from the other three groups by marked differences: a significantly higher rate of unmarried mothers, financial difficulties, absence of mental illness, and admission of not wanting an illegitimate child. The common methods of murder identified are head trauma, drowning, suffocation, and strangulation. Women who accidentally killed their young children during an episode of abuse shared characteristics with mothers who commit neonaticide, including being young, poor, unemployed, single, and without a suicide attempt following the act.
In a study performed by Helmi et al., in Zenhom Mortem in Cairo in the period 1977-1979 and included forty two criminal neonatal cases, they found that twenty cases were died from omission and seventeen cases were died due to commission while fifty two cases were found to be due to noncriminal causes (Helmi et al., 1979).

In another study performed by ElSharkawy et al., during the period 2002-2005 in Assiut Medicolegal Department, Egyptian forensic Medicine Authority and included thirty two cases of neonatal deaths, the commonest cause of death in their study was omission of infants $(18.75 \%)$, while death due to head injury is found to be responsible for $(12.5 \%)$ of cases. They found also that death due to asphyxial causes (smothering and drowning) comprised $(6.3 \%)$ of the cases (El- Sharkawy et al., 2007).

In our study, the cause of death was due to violent asphyxia in five cases; which comprised $(6.7 \%)$ of total studied cases and $(33.3 \%)$ of the neonaticides, of which three cases were due to strangulation and two cases were due to smothering.

Bruises and abrasion around the neck with face congestion, cyanosis and petechial hemorrhages on mucous membranes are constant features seen in strangulation cases. The used robe may also be found in place. While bruises around the nose and mouth with finger nail abrasions are seen in cases of smothering. Sometimes, it is very hard to see any of these signs which subsequently mislead the diagnosis of cause of death (Herman-Giddens et al., 2003).

In a case series derived from data on all deaths among live born infants 0 to 4 days of age reported to the North 
Carolina medical examiner from 1985 through 2000, the most common causes of death were asphyxiation/strangulation (41.1\%) and drowning $(26.5 \%)$. The data indicate that in North Carolina, at least 2.1 per 100000 newborns are known to be killed or left to die per year, usually by their mothers (Herman-Giddens et al., 2003).

In our study, the cause of death couldn't be determined in $(12 \%)$ of cases; and this could be referred mainly to advanced putrefaction.

In a study by El- Sharkawy et al., they couldn't identify the cause of death in $46.88 \%$ of cases due to advanced putrefaction of the corpses (ElSharkawy et al., 2007).

In cooperation with the Crime Investigation Agency or Landeskriminalamt (LKA), in Germany, of North Rhine-Westphalia, 150 cases of suspected neonaticide dating from 1993 to 2007 from all over Germany were investigated. The autopsy reports and additional expert opinions were evaluated for a minimum of 78 variables. Of the corpses, $27 \%$ were in a state of such severe putrefaction that forensic examination was limited. The main causes of death were all forms of suffocation (Schulte et al., 2013).

In the current study, one case was found to have cut throat, which was committed by a sharp blade, and death was due to irreversible hemorrhagic shock. Fire-arm injuries and injuries due to dropping from height were not recorded in the current study.

Although fathers are rarely responsible for neonaticides, they use active and violent means, such as shooting, stabbing, hitting, dropping, squeezing, crushing, or shaking, in order to kill their children (West, 2007 and Resnick, 1970).
In Switzerland, the prevalence and phenomenon of neonaticide were analyzed using data from judicial files in 15 German-speaking cantons between 1980 and 2010. The sample included uncommon cases of nonmaternal neonaticide; fathers were found to be the perpetrators (Krïger, 2015).

Unfortunately, there is no enough data available about the perpetrators in documentations referred to Cairo Morgue; Egyptian Forensic Medicine Authority.

In the present study, thirty-one cases were found to be males $(41.3 \%)$ and forty three cases were females $(57.3 \%)$. In one case, the sex couldn't be determined due to advanced putrefaction. Regarding the neonaticides; three cases were males (20\%) while twelve cases were females $(80 \%)$, and thus demonstrating the higher ratio of female killing compared to males in this study.

Infant Killing today continues at a much higher rate in areas of extremely high poverty and overpopulation, such as parts of China and India. Female infants are particularly vulnerable, a factor in sex-selective infanticide. The policy of one child in china is a grave example of gender selection where female newborn murder is very clear (Quanbao et al., 2005).

In a study performed during the period from 1998 to 2008, at the Hamburg Institute of Legal Medicine, and included thirteen cases in which an investigation for neonaticide had been initiated by the public prosecutor. The killed neonates showed a nearly equal distribution between both sexes. The most common method of neonaticide was suffocation. Most of the perpetrators were young, unmarried primipara with an average educational 
background. Almost all of them were suffering under psychological stress and had negated their pregnancy. In most cases, birth and neonaticide happened alone in their flat, and there was no medical attendance in any case (Krohn et al., 2011).

Unfortunately again, there is no enough data available about the perpetrators in documentations referred to Cairo Morgue; Egyptian Forensic Medicine Authority.

\section{CONCLUSION}

From the current study, we concluded that neonatal killing (neonaticide) is a problem in Cairo. The crime is usually committed by different ways, of which the commonest was by blunt trauma. Gender selection and male preference aggravate the problem. The problem must be thoroughly investigated and carefully studied from different perspectives with enough data about the perpetrators, in order to achieve a reasonable solution.

\section{REFERENCES}

Bätje C, Schläfke D, Nedopil N,and Hässler F. (2011): Infanticide. Social and forensic aspects. Nervenarzt. 82(7):873-9.

Bourget D, Grace J, and Whitehurst L. (2007): A review of maternal and paternal filicide. J Am Acad Psychiatry Law. 35(1):74-82.

El- Sharkawy S., Abdel- Maaboud R., Mohamed A. et al. (2007): The medicolegal aspects of infanticide cases. Available at: https://repository.nauss.edu.sa/hand le/123456789/56428. Accessed at: April 2018.

Encyclopedia of the Qur'an, (2016): Children. Available athttps://en.wikipedia.org/wiki/Infa nticide.

Helmi Z., Elnayl N., Elmelegi M. and Elsigini A. (1979): "Infanticide". Master degree in medical thesis, Ain Shams University, Egypt.

Herman-Giddens ME, Smith JB, Mittal M, et al. (2003): Newborns killed or left to die by a parent: a population-based study. JAMA.289 (11):1425-9.

Krohn J, Anders S, Püschel K, and Schröder AS., (2011): Neonaticides in Hamburg, Germany, from 1998 to 2008. Arch Kriminol. 227(56):174-80.

Krüger P. (2015): Prevalence and phenomenology of neonaticide in Switzerland 1980-2010: a retrospective study. Violence Vict. 30(2):194-207.

Piers MW. (1976): Infanticide - a historical review. Psyche (Stuttg). 30(5):418-35.

Quanbao J., Marcus W., and Xiaoyi J. (2005): Estimation of the Number of Missing Females in China: 1900-2000. Available 24 October 2016 at http://iussp.princeton.edu/papers/51 345.

Rammouz I, Tahiri DA, Aalouane R, et al. (2008): Infanticide in the postpartum period: about a clinical case. Encephale. 34(3):284-8.

Resnick PJ. (1970): Child murder by parents: a psychiatric review of filicide. Am J Psychiatry. 126:32534.

Schöne M, Peter E, Dobrowolny H, and Bogerts B. (2015): Neonaticide: a classification of female perpetrators in an east-west comparison. Nervenarzt. 86(5):595602.

Schulte B, Rothschild M, Vennemann $M$ and Banaschak $S$. (2013): Examination of (suspected) 
neonaticides in Germany: a critical report on a comparative study. Int $\mathbf{J}$ Legal Med. 127(3):621-5.

Spinelli MG. (2005): Infanticide: contrasting views. Arch Women's Ment Health. 8(1):15-24.

Taguchi H. (2007): Maternal filicide in Japan: analyses of 96 cases and future directions for prevention.
Seishin Shinkeigaku Zasshi. 109(2):110-27.

Teeter Emily (1999): Egypt and the Egyptians. Cambridge University Press. ISBN 0521449847.

West S. (2007): An Overview of Filicide. (Edgmont).4(2): 48-57. 


\section{نمط واتنشار حالات قتل الأطفال حديثي الولادة في محافظة القاهرة خلال عامي

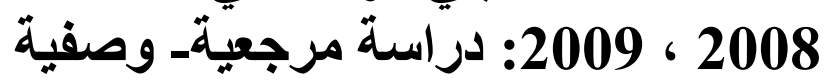

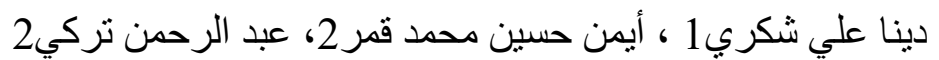

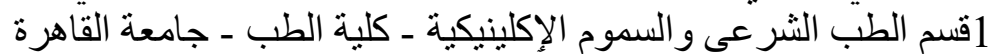

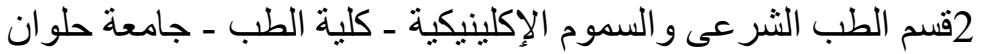

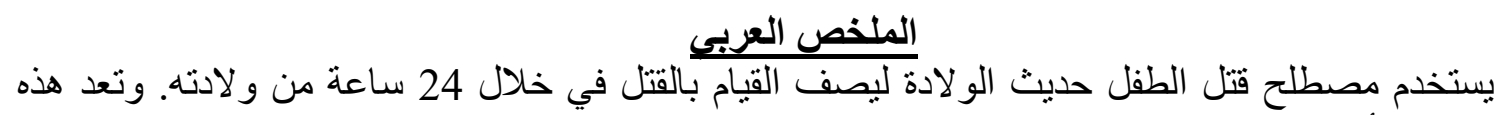

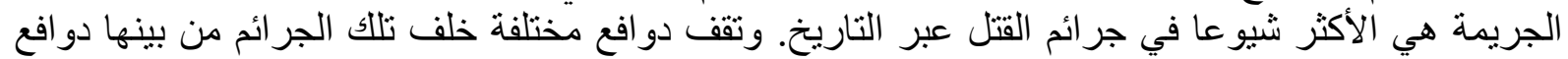

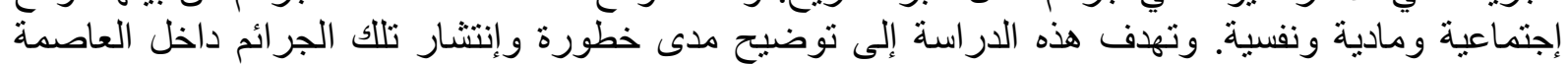

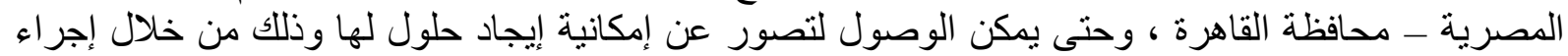

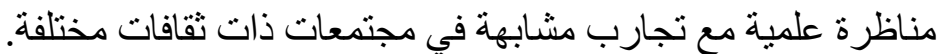

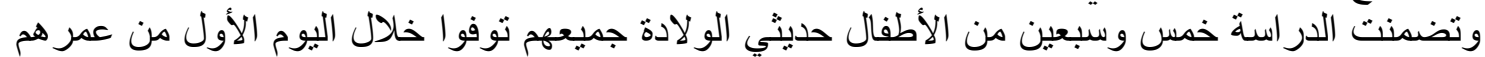
و التي حولت إلى مشرحة القاهرة في العامين 2008 و 2009. حيث تم دراسة بيانات هذه الأه الحالات دراسة مرجعية وصفية. و أظهرت النتائج أن عشرين بالمائة من تلك الحالات ثبت وفاتها جنائيا ، بينما ست وستين وسبع أعشار

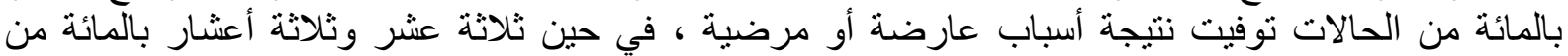
الحالات لم بمكن تحديد طريقة الوفاة.

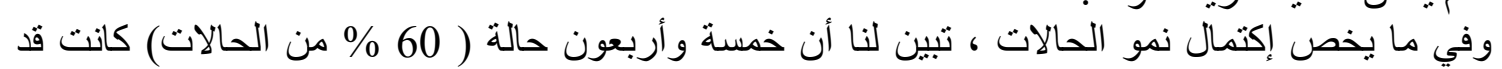

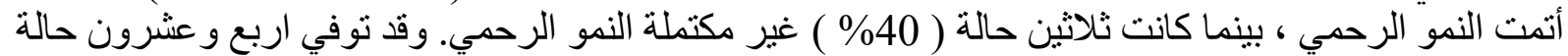

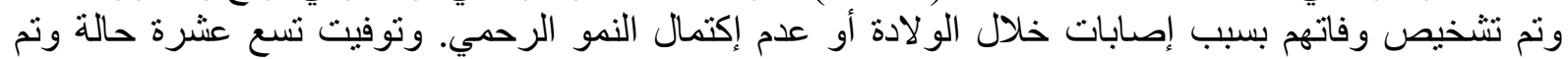

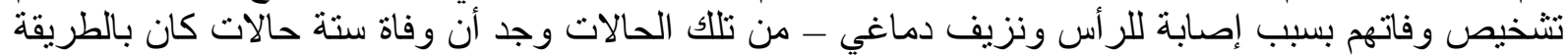
الجنائية. بينما كانت الوفاة بأسباب تتعلق بمشاكل التنفس أو بمشاكل الجهاز الدوري و القلب تمثل عدد ثلاثة عشر التر

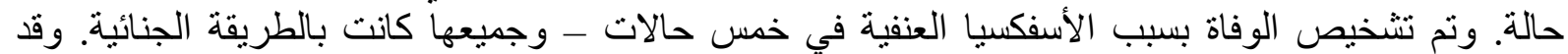

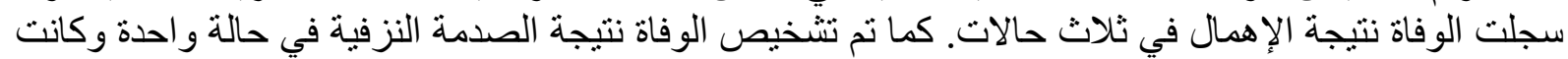
وفاتها بطريقة جنائية. كذلك تم تشخيص الوفاة نتيجة العيوب التخليقية في حالة واحدة وكاة وكانت الوفاة بطريقة فير ولئ جنائية.

هذا وقد اتضح من الدراسة أن قتل الأطفال حديثي الو لادة (وخاصة الإناث منهم) يمثل مشكلة في محافظة

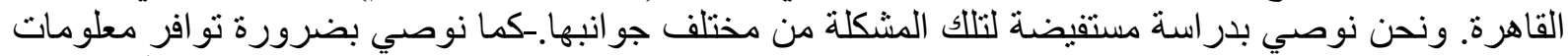
كافية عن مرتكبي هذه الجريمة بعد الانتهاء من التحقيق بها و إلحاقها بالتقارير لار أستها ومعرفة الأسباب في ني محاولة للوصول إلى حلى هلول مناسبة لهذه المشكلة. 